\title{
0 "Ajustamento" e os Impactos, Consequências e Alterações Decorrentes - as Relações Externas de Portugal ${ }^{1}$
}

Pedro Ponte e Sousa

Daniela Braziela 


\section{RESUMO:}

A crise financeira internacional de 20072008 , criando terreno para a crise das dívidas soberanas que se seguiria, tiveram forte impacto no país, no seu PIB, desemprego e dívida pública. Ao cabo de três anos do pedido de assistência financeira do governo português ao FMI, BCE e Comissão Europeia (vulgo troika), interessa compreender se esta intervenção austeritária, com âmbito nas finanças públicas, estabilização financeira e competitividade, provocou alterações assinaláveis na política externa portuguesa, em particular no âmbito económico. Para tal, analisaremos: os programas dos governos mais recentes e a nova "diplomacia económica", os documentos acordados entre o Estado português e as instituições internacionais, variáveis macroeconómicas relevantes, e demais documentação, discursos e notícias. Interessanos, em particular,

\section{Introdução: Enquadramento teórico e relevância da análise}

A forma superficial e pouco enquadrada a nível teórico como normalmente são tratados os fenómenos de Política Externa dificulta grandemente tanto a compreensão das suas várias dimensões em análise em acção, bem como dinâmicas e actores. Ao mesmo tempo, e tendo em conta a tão grande complexidade de tais fenómenos, tais dificuldades têm também trabalhado para impedir a formação de um corpo de conhecimentos que auxilie a compreensão e explicação de fenómenos internacionais relevantes (Freire e Vinha, 2011; Mendes, 2012). Partiremos, aqui, da definição de política externa da autoria de Freire e Vinha (2011: 18): «O conjunto de objectivos, estratégias e instrumentos que decisores dotados de autoridade escolhem e aplicam a entidades externas à sua jurisdição política, bem como os resultados não intencionais dessas acções». Os trabalhos na área, entre outros problemas, são demarcadamente histórico-descritivos (Mendes, 2012), que tanto se focam nos imperativos de contexto, decorrentes do ambiente externo, como dependem do Realismo como Teoria das Relações Internacionais, numa visão que não problematiza as decisões do Estado em matéria de política externa (Nogueira e Messari, 2005; Mendes, 2012).

O surgimento de uma abordagem teórica que tendesse para a criação de modelos e análises próprios ocorre apenas no final da Segunda Guerra Mundial. A Análise de Política Externa (ou Foreign Policy Analysis, em inglês) emerge com uma série de trabalhos pioneiros que enfocam: a necessidade da compreensão comparada da política externa, e de encontrar ou identificar factos transnacionais que pudessem, portanto, ser generalizáveis; o papel do indivíduo como actor essencial na decisão de política externa; e ainda o meio, o contexto em que tais decisões são tomadas, quer seja o meio social ou psicológico, entre muitos outros factores (Freire e Vinha, 2011; Hudson e Vore, 1995; Hudson, 2005). Estas teorias, mais particulares do que as teorias gerais das Relações Internacionais, e portanto, com melhor capacidade para enquadrar e compreender a especificidade, o detalhe, e a acção concreta na vida internacional, conseguiram salientar, entre outros aspectos, a importância dos vários níveis de análise, nomeadamente a interpenetração dos fenómenos de política interna e externa, e a importância do processo de decisão em si (Rados, 2003; Mendes, 2012; Sousa, 2005).

As questões apontadas atrás são ainda mais relevantes no contexto de um pequeno estado como Portugal. Na verdade, tais problemas são ampliáveis, particularmente num contexto em que tanto a produção científica é de menor quantidade como a 
discussão pública de tais temas é mais reduzida. Adicionando-se a estes factores o regime ditatorial português de quase meio século, e uma democracia ainda bastante jovem que lhe é sucedânea (Mongiardim, 2007), e estão reunidas as condições para que tal tema esteja ainda «menos exposto à consideração da opinião pública» (Dougherty e Pfaltzgraff, 2003: 704) do que normalmente ocorreria, portanto afastando-se a discussão e o seu interesse, tornando-a uma questão meramente técnica (Patrício, 2014). Aliás, tal é facto é especialmente corroborado, no caso português, pelo amplo consenso que é atribuído a praticamente todas as grandes prioridades de política externa portuguesa, pelos três partidos que já assumiram funções governativas: PS, PSD e CDS

Assim, e relativamente a este trabalho, procuraremos descortinar alguns indicadores que nos possam certificar, de forma obviamente preliminar, se existiram mudanças significativas na política externa durante ou devidas ao Programa de Ajustamento Económico e Financeiro, ou seja, de 2011 em diante. Restringir-nos-emos à dimensão económica de tal política externa, ou seja, se há alterações significativas de política externa portuguesa no que toca a parceiros comerciais e de investimento, e se essas decorrem de obrigações expressas no âmbito dos acordos de assistência financeira ao governo português (ou seja, explicitamente indicadas nos acordos com o FMI, BCE e Comissão Europeia, vulgo troika), ou, ao invés, de um objectivo definido pelos governos em funções. Assim, exploraremos temas que têm vindo a ganhar relevância, como a "nova diplomacia económica", analisaremos tanto os acordos supracitados como, de forma mais geral, os programas de governo das legislaturas mais recentes, e examinaremos ainda as variáveis macroeconómicas relevantes para o tema, demais documentação, discursos e notícias. Deste modo, estreitaremos esta análise para a dimensão que, acreditamos, poderá ter sido mais permeável à mudança neste período: as relações económico-comerciais com o exterior - assumindo que os grandes eixos da política externa portuguesa (ou até o national role que esse país assume ou procura assumir na cena internacional (Patrício, 2014)) não sofreram modificações de monta durante esses anos.

\section{Contexto histórico: a crise financeira internacional e a crise das dívidas soberanas}

A crise bancária e a crise financeira, mais global e que se lhe seguiu, dos anos 2007-08, produziram consequências de magnitude excepcional (normalmente é compreender se o peso dos parceiros (relações bilaterais estruturais, nomeadamente comerciais) se alterou significativamente e apontar possíveis pistas (fontes, impulsos) para tais alterações; mas também se Portugal se terá centrado, neste período, em países com os quais as relações já eram fortes como suporte para a saída da crise económica, ou se procurou efetivamente parceiros novos e inesperados, tentando atestar se as relações externas portuguesas foram afetadas significativamente pela intervenção da troika atendendo a possíveis alterações de prioridades e objetivos do Estado português.

\section{PALAVRAS-CHAVE}

Crise financeira;

Programa de ajustamento económico e financeiro; política externa portuguesa; relações comerciais bilaterais; diplomacia económica 
apenas comparada à crise decorrente do crash da bolsa de 1929), com severas consequências no âmbito do (des)emprego e da pobreza. A financeirização e desregulamentação do sistema financeiro, decorrentes da ideologia neoliberal, são tidos como uma das possíveis causas ${ }^{2}$ desta crise financeira em países ricos. Outra normalmente apontada são as baixas taxas de juro, durante um período de tempo bastante (excessivamente?) prolongado, definidas pelos bancos centrais, e, em particular, pela Reserva Federal Norte-Americana (FED), desde o início da década - ou seja, tida como uma política monetária (exógena) errada que causa uma crise nos mercados. Há ainda quem evidencie o grande défice de conta corrente dos EUA (mais importações que exportações) como causando um enfraquecimento significativo do dólar, e, portanto, desestabilização o sistema financeiro como um todo. Por fim, salientam-se os antecedentes da crise financeira geral, a chamada crise dos subprimes, de «hipotecas oferecidas a clientes de qualidade de crédito inferior que eram depois agrupadas em títulos complexos e opacos, cujo risco associado era de avaliação difícil, senão impossível, para os compradores» (Bresser-Pereira, 2010: 53). O sistema financeiro tornava-se mais arriscado e frágil (embora mais integrado) e assente nas inovações e especulação financeira (fomentada também pelo desenvolvimento das tecnologias). Do capitalismo organizado e burocrático passou-se para um capitalismo financeiro e instável. Aquela financeirização decorre a par da liberalização dos mercados financeiros e do incremento dos fluxos financeiros mundiais, e assenta no uso de instrumentos financeiros para aumentar o valor dos activos financeiros; uma separação entre a economia real e a economia financeira; e grande aumento dos lucros das instituições financeiras. Em suma, a operação bancária transfere-se dos empréstimos às empresas para fundos e investimentos em títulos financeiros - riqueza real e financeira distanciam-se, em operações complexas que diluem a percepção do risco, e passando estes últimos a assegurar uma parte crescente da riqueza real. Famílias crescentemente endividadas enquanto os rendimentos do trabalho estagnam, conduzem a hipotecas que as famílias não conseguem pagar. Este é um problema agravado pela fraude com subprimes, bem como uma especulação financiada a crédito, que geram o risco, a quebra de confiança, o pânico e a crise em finais de 2008 - todos estes largamente exacerbados pela decisão de deixar falir o Lehman Brothers nessa mesma altura.

"Quando irrompeu a crise, os políticos, que haviam sido iludidos pela ilusão da natureza auto-regulada dos mercados, perceberam seu erro e tomaram quatro decisões: primeiro, aumentar radicalmente a liquidez por meio da redução da taxa básica de juros (e todos os demais meios possíveis), já que a crise implicava 
um grande aperto de crédito após a perda generalizada de confiança que causou; segundo, resgatar e recapitalizar os principais bancos, por serem instituições quase públicas que não podem ir a falência; terceiro, adotar políticas fiscais expansionistas que se tornaram inevitáveis quando a taxa de juros atingiu a zona de armadilha de liquidez; e, quarto, regular novamente o sistema financeiro, tanto domestica como internacionalmente. (...) Perceberam que o capitalismo moderno exige não desregulação, mas regulação; que a regulação não impede, mas permite a coordenação da economia pelo mercado; que quanto mais complexa uma economia nacional, mais regulada precisa ser se desejarmos nos beneficiar das vantagens da alocação ou coordenação de recursos pelo mercado; que a política económica deve estimular o investimento e manter a economia estável, não ajustar-se a princípios ideológicos; e que o sistema financeiro deve financiar investimentos produtivos, não alimentar a especulação» (Bresser-Pereira, 2010, pp. 66-7)3.

De facto, os Estados, depois de, pela tomada de medidas excepcionais, nacionalizarem o sistema bancário e evitarem o seu colapso, e começarem por tomar medidas contra-cíclicas, vêem as suas dívidas soberanas a serem também elas atacadas. A crise espalha-se dos EUA para a Europa e, depois das nacionalizações (e a correspondente sobrecarga na dívida pública), torna-se mais difícil tentar dirigir as economias. Ainda assim, a contracção orçamental que se seguiu, a partir de 2010, tem impactos muito negativos na actividade económica, imediatamente depois de uma recuperação muito frágil. Tanto o FMI como a OCDE apelaram, durante esse ano, a uma consolidação orçamental e reformas estruturais em larga escala a iniciar o mais rapidamente possível, com o amparo (tácito) do G20. Causas e consequências da crise foram misturadas (resgate e recapitalização dos bancos; menores receitas governamentais pelo abrandamento económico; políticas de estímulo económico versus níveis elevados de dívida e défice públicos), e os argumentos pela austeridade ganharam peso. Reduzir a estrutura e intervenção estatal para reduzir o défice e dar maior segurança aos mercados eram os meios e objectivos propostos (Ortiz \& Cummins, 2013)4. Vários autores (de onde se salientam as críticas mais ferozes e reconhecidas de Stiglitz e Krugman) têm acentuado que «com os programas sucessivos de austeridade, há uma diminuição de procura de bens e uma diminuição do Produto Interno Bruto (PIB) e, consequentemente, uma redução de receitas fiscais, ao mesmo tempo que aumentam as dívidas privada e pública» (Silva, 2013). Diminuição de rendimentos, destruição de empregos, e até impactos significativos no desenvolvimento no longo-prazo, ao mesmo tempo que as medidas adoptadas aumentam as desigualdades e penalizam mais os salários do que os restantes rendimentos. A estratégia de coordenação de 
políticas económicas para saída da recessão transforma-se num plano onde cada país é responsável por reestabelecer o equilíbrio dos seus orçamentos. A maioria das "medidas de ajustamento" que tem sido considerada, por todo o mundo, tanto em países sob programas do FMI ou da troika como países que não sentiram tal necessidade, tem se centrado em: reduzir ou eliminar subsídios (ou subvenções); reduzir ou manter salários; aumentar impostos sobre o consumo (IVA) (estas são as mais comuns); outras, igualmente muito utilizadas, são a reforma do sistema de pensões (aumentar períodos de contribuição, idade da reforma ou reduzir prestações, etc.), redução da protecção social aos mais pobres; no caso dos países mais ricos, também têm sido promovidas reformas do sistema de saúde e do mercado de trabalho5.

Portugal é um dos países mais afectados por esta segunda crise. Depois de resgatado e recapitalizado o BPN (Banco Português de Negócios), para além de outras incidências do sistema financeiro português, por toda a Europa a especulação internacional e o efeito dominó no Sul da Europa forçaram cortes de grande dimensão nas despesas estatais, ou até resgates financeiros, conduzidos, em conjunto, por entidades europeias (Comissão Europeia e Banco Central Europeu) e pelo FMI. Assim, estes avaliaram as necessidades de financiamento do país, e negociaram as condições do resgate, avaliando-o regularmente. Vários líderes políticos foram forçados a resignar, e novos governos, de tecnocratas e/ou apoiados por dois partidos ou mais, chegaram ao poder - e, no caso português, o governo de José Sócrates cai após a não aprovação de um programa de austeridade (vulgo PEC4), pelo que o governo se demite e, das eleições subsequentes, sai eleita uma coligação de direita (Bellucci, Lobo \& Lewis-Beck, 2012). Surge o termo "PIGS" (ou PI(I)GS) para descrever países cuja fragilidade política e económica colocava em risco os investimentos financeiros.

\section{Pedido de assistência financeira por Portugal. Três anos de intervenção económica e financeira}

Com o défice e o desemprego nos dois dígitos, e sem crescimento visível, no início de 2010 o governo de José Sócrates começa a implementar programas para reduzir os gastos públicos, os chamados "Programa(s) de Estabilidade e Crescimento", apoiados tanto pelo Presidente da República como pelo líder do partido da oposição. Ao longo desse ano, três programas de austeridade são apresentados - a confiança no governo decresce a olhos vistos, e o Presidente da República, 
acabado de reeleger, aumenta as críticas ao governo. Durante esse ano, o défice não se contraiu significativamente, o desemprego continuou a aumentar, a dívida pública aumentou em 10 pontos, e apenas o PIB, ainda a crescer, se mostrava como único sinal positivo. Um quarto pacote de austeridade, proposto em Março de 2011 é rejeitado por todos os partidos da oposição, pelo que o Primeiro-Ministro decide resignar ao cargo. A partir deste momento, a ajuda externa, que aquele tinha evitado durante meses pedir, acabaria por ser requerida ao FMI e à União Europeia (Fundo Europeu de Estabilização Financeira), implementando, entre outras, as medidas anteriormente rejeitadas (aquando do PEC 4), e envolvendo o PS, PSD e CDS-PP. Das eleições de Junho sai como vencedor o líder do PSD, que se propõe actuar em conformidade com o memorando, e ir até mais além nos programas de privatizações e nas reformas laborais, entre outros (Freire \& Santana-Pereira, 2012).

Essa ajuda financeira, a ser prestada num período de três anos, e com um montante total de 78 mil milhões de euros, estaria disponível ao país em várias "prestações" (ou tranches), sujeitas a condicionalidade. Essa condicionalidade, definida à partida tanto no memorando acordado com o FMI como com a União Europeia envolvia uma série de políticas para as finanças públicas, estabilidade financeira e promoção da competitividade. Uma série de tais objectivos remetem para medidas prévias que o Governo português deveria pôr em acção (nomeadamente levantamento de estatísticas e despesas, bem como elaboração de relatórios), enquanto outras, tidas por cruciais para o sucesso do programa, apresentam-se como de "condicionalidade estrutural" (e, portanto, prioritárias e essenciais). Assim, referimo-nos a políticas macroeconómicas ou estruturais, bem como ferramentas específicas para que estas organizações consigam avaliam o cumprimento das metas definidas (Banco de Portugal, 2011).

Desemprego, salários em atraso, ameaça de despedimento, impossibilidade de cumprir compromissos, casas penhoradas, e «com cortes nos subsídios, pensões e salários, com a eventual quebra das margens de poupança e o congelamento do crédito, as empresas e as famílias têm cada vez maiores dificuldades de fazer face a despesas correntes» (Silva, 2013). Estas são algumas das consequências mais visíveis dos anos de austeridade em Portugal, para lá das estatísticas já recorrentes (retracção do PIB, e crescimentos do desemprego e da dívida pública do país). 


\section{Política externa portuguesa: contextualização, século XXI, programas de governo}

«Pequena potência, semiperiférica e com uma só fronteira terrestre, Portugal viveu, sempre, um equilíbrio instável, entre a pressão continental e a procura de uma alternativa marítima» (Teixeira, 2010). A mudança de regime promovida pelo Movimento das Forças Armadas propunha-se claramente à democratização, descolonização e desenvolvimento, e, no período constitucional, os governos que se constituem apostam sem dúvidas nos vectores atlântico e europeu de posicionamento do país na cena internacional (Ferreira, 1988). Diferentes autores salientarão mais as relações políticas e de segurança (Estados Unidos da América e NATO) para consolidar a "orientação externa» e a "estabilização interna» do país (Teixeira, 2010), enquanto outros autores reforçam o papel de estados e instituições europeus e de interesses económicos para tal transição - e, portanto, de uma reorientação da política externa para a Europa (incluindo a adesão ao processo de integração) (Vicente, 2013) ${ }^{6}$. Seguir-se-á a reaproximação aos recém-independentes PALOP (Países Africanos de Língua Oficial Portuguesa), um processo demorado mas que dará frutos com a criação da CPLP (Comunidade dos Países de Língua Portuguesa), cimentando esta como a terceira e última variante da Política Externa Portuguesa, atenta nas relações pós-coloniais (num contexto de cooperação e promoção da língua e cultura). Por fim, alguns autores propõem este século em que nos encontramos como sendo o período da diplomacia económica, em que a diplomacia ganha um novo rumo, quando a diplomacia bilateral perde importância, e desaparecem (estados) opositores políticos claros como impedindo a prossecução dos objectivos de política externa de um país. Ao mesmo tempo, as relações económicas internacionais, com a liberalização das trocas e fluxos de capitais, tornam-se progressivamente mais relevantes para a vida dos estados (Castro, 2008) ${ }^{7}$.

João Cravinho vê uma política externa consolidada, num país antigo que não é favorecido por rápidas mudanças, continuidade que exige adaptações constantes. Essas alterações não farão abandonar os anteriores pilares, mas aumentar e alargar a presença na cena internacional, em particular através do multilateralismo e cooperação (nomeadamente, no âmbito de mecanismos internacionais de estabilidade e de segurança), e da relação com novos pólos de poder como os países emergentes (Cravinho, 2011). De facto, e particularmente para o século XXI, é perfeitamente perceptível que não se identificam tendências ou prioridades muito diferentes das de períodos anteriores podendo ser um indicador de que a política 
externa portuguesa não tem alterações apresentáveis de substância significativa nos últimos tempos.

A análise dos programas de governo (a que procedemos noutros trabalhos), em particular no que concerne à política externa, corroboraria completamente esta afirmação. Decompor o discurso produzido pelos actores, a par da efectiva prática e papel dos actores no Sistema Internacional, sempre que necessário, esclarecendo algumas das forças que estruturam o posicionamento deste país na cena internacional e sua evolução, foi o que se tentou fazer quando nos propusemos a analisar as promessas e propostas de orientação, pelo menos declarada, para a política externa no início das legislaturas, neste novo século e até ao presente. Como já vimos, num período estabilizado da democracia (e até, da política externa, segundo Severiano Teixeira), e estando Portugal plenamente introduzido no processo de integração europeia. De facto, ao longo do século XXI, podemos apenas notar como alterações significativas o aumento de importância da CPLP e, particularmente desde 2005, da "diplomacia económica". Na verdade, estas tendências parecem emergir enquanto não se eliminam outras - há algumas alterações nas prioridades e formas de as conseguir de governo para governo (e algumas ligadas até à cor política - que não discutiremos aqui porque já foram tratadas noutros trabalhos), mas, no essencial, estas são as tendências que mais se destacam. Atendendo à tendência estrutural de aumento de peso das políticas pós-coloniais, centrar-nos-emos fundamentalmente na questão da diplomacia económica, e em particular no programa do governo em funções, o XIX Governo Constitucional.

A diplomacia económica e a internacionalização da economia portuguesa é um tema referido em todos os programas de governo, embora com pesos bastante díspares. Melhor coordenação entre organismos, um maior papel da diplomacia portuguesa e da rede consular nestes objectivos "económicos", prioridade aos países de língua oficial portuguesa (Fórum Empresarial da CPLP - Santana Lopes), são propósitos mais referidos nos programas dos governos que vigoraram entre 1999 e 2005 (Programa do XIV Governo Constitucional, 1999; Programa do XV Governo Constitucional, 2002; Programa do XVI Governo Constitucional, 2004). O primeiro governo de José Sócrates parece reforçar tais intuitos, declarando querer facilitar a acção dos agentes económicos e estimular o investimento externo, com regras claras, simples e estáveis - tendo por meta o emprego, competitividade externa, maior oferta de bens transacionáveis e equilibrar a balança externa (Programa do XVII Governo Constitucional, 2005) ${ }^{8}$. Aquando do seu segundo 
mandato (já durante a crise financeira internacional), pretende-se o reforço de tais instrumentos, e concretizam-se a participação em feiras internacionais, fontes de financiamento internacional, o papel das embaixadas nas redes de conhecimento e captação de investimento externo e a parceria com os empresários da diáspora como outras prioridades. Assim, "o novo impulso a dar à internacionalização da economia portuguesa deve assumir-se como prioridade da acção externa do Governo português» (Programa do XVIII Governo Constitucional, 2009). Por fim, o XIX Governo Constitucional (Passos Coelho) parece ter como único objectivo de política externa para o seu mandato a diplomacia económica para recuperar credibilidade externa e atrair investimento estrangeiro, ao mesmo tempo que internacionaliza a economia. Todas as funções "tradicionais" ficar-lhe-ão submetidas, ligar-se-á a política interna à política externa, aumentando as exportações. Desta forma, apresenta uma série de objectivos coordenados especificamente para este propósito, o que até agora nenhum governo havia feito: coordenação com as empresas nos mercados externos, tentando desburocratizar a sua acção externa; eliminar casos de dupla tributação existentes; apoiar consórcios de empresas e redes integradas, reforçar a "marca Portugal" e a acção de câmaras de comércio. Para além disso, relações com a CPLP e as comunidades portuguesas no exterior deverão ser reorientadas para este propósito sempre que possível ${ }^{9}$. Como nota final, saliente-se apenas que nenhum dos governos se afastou significativamente dos eixos estratégicos há muito definidos, e apenas o último, tendo encarado uma situação conjuntural muito difícil, procura que a política externa, já "consolidada" e de "consenso" (Programa do XIX Governo Constitucional, 2011) esteja quase totalmente subordinada a um outro imperativo - a diplomacia económica.

\section{Diplomacia económica: conceito, implicações, política externa portuguesa}

Mas o que queremos dizer exactamente com "diplomacia económica"10? Ela é, de facto, diferente da diplomacia que os estados praticavam, implica novos meios ou objectivos? Paulo Portas, actual Ministro de Estado e dos Negócios Estrangeiros, refere-se, no Seminário Diplomático de 2013, ao móbil de integração das redes diplomática, económica e de promoção turística, transformando as embaixadas e os consulados, «hoje, mais do que nunca, [em] centros de negócios para as empresas, produtos e marcas de Portugal no exterior», afirmando como cumpridas «a coincidência entre visitas oficiais e políticas e missões empresariais, (...) a colaboração entre departamentos governamentais, ministérios e agências», para 
aumentar exportações, missões de investimento estrangeiro no nosso país, «sejam os seminários sobre mercados, sejam as ações de capacitação das empresas para se internacionalizarem» (Negócios Estrangeiros - Seminário Diplomático, 2013 $)^{11}$. Para o presidente da AICEP à data (Pedro Reis), a diplomacia nunca se excluiu das questões económicas e se centrou apenas e só nos assuntos políticos; «a diplomacia económica, mesmo se oferece aos agentes económicos privados um espaço de promoção dos seus interesses próprios, deve servir sobretudo o interesse público: empresas e empresários (...) servem o interesse da coletividade nacional, num ciclo virtuoso de mútuo reforço das duas esferas: tanto da privada como da pública». Assim, o alvo será «detect[ar] e monitoriz[ar] que sectores interessa promover prioritariamente, que tipo de investimentos importa captar em primeiro lugar, junto de que mercados deve ser promovida a produção industrial ou a oferta turística e que países ou regiões deverão constituir o alvo preferencial da diplomacia económica» (Negócios Estrangeiros - Seminário Diplomático, 2012). Já para o administrador da AICEP (António de Almeida Lima), com esta ênfase na diplomacia económica o que se pretende essencialmente «é uma melhor e mais eficiente articulação de todos os intervenientes no processo de internacionalização da economia ${ }^{12}$.

Para alguns autores, «o contexto económico e político mundial sofreu nas últimas décadas mudanças significativas que impeliram os estados a procurarem novas abordagens em defesa dos seus interesses, nomeadamente económicos e políticos, (...) traz[endo] responsabilidades acrescidas para a defesa dos interesses estratégicos dos estados sendo a componente económica incontornável». Em consequência, «nunca, como agora, a diplomacia económica assume papel de tão grande relevância enquanto componente essencial da política externa e em apoio à internacionalização das economias e das empresas» (Ferreira \& Gonçalves, 2009). Maria Sousa Galito defende aliás que «a diplomacia económica sempre existiu. Os chefes de Estado e de Governo há séculos que apoiam mercadores e promovem trocas comerciais, ao enviar mensageiros para negociar acordos. A diplomacia económica é instrumental e intermediária. Progrediu naturalmente para se adaptar à actualidade» (Galito, 2011) ${ }^{13}$. De facto, parece que estamos num período de transição de uma diplomacia económica de exploração, políticas agressivas e partilha do mundo (até à $1^{\text {a }}$ Guerra Mundial), e de uma ordem de negociações e acordos multilaterais (até à década de 70) para um acompanhamento e estímulo da actividade das empresas, tanto das "nacionais" no exterior do país, como das estrangeiras no seu interior (Leal, 2007). «Na concepção tradicional da diplo- 
macia, isto é, nas considerações clássicas de política externa, essa relação dual [interacção entre diplomacia e economia] se colocava entre a política externa e os instrumentos militares, ou seja, o poderio estratégico de um determinado país e sua projeção externa. Nas condições actuais (...) essa relação deve ser vista como envolvendo basicamente o mundo econômico (indústria, comércio, investimentos, finanças, tecnologia, recursos humanos, enfim, os grandes determinantes da produtividade e da competitividade contemporânea)» (Almeida, 2009). Mas «um país que não possua uma boa percepção, explicitação e instrumentação da diplomacia económica, dificilmente potenciará as vantagens e minimizará os custos deste instrumento de trabalho. Torna-se alvo fácil de modelos estrangeiros mais eficientes ou da acção não estadual, mas estratégica, de agentes e agências mais experientes nesta matéria» (Galito, 2011). Missões comerciais e planos de negócios ajudariam à concretização de tais objectivos.

Ainda assim, «a conjugação de inúmeros vectores na arena internacional deve transpor a projecção e a dinamização da venda da imagem de um estado, tendo apenas por objectivo o crescimento económico e a captação de investimento directo externo enquanto a população ou sociedade civil acompanha o processo" (Martins, 2011), relembrando-nos de que a "diplomacia económica" não pode nunca ser o único propósito da política externa de um país. Embora se compreenda que a diplomacia se tem que ir adaptando a novas realidades, "os objectivos a prosseguir na política externa (...) não se esgotam na criação de condições externas favoráveis ao bem-estar e progresso económico dos povos. Há fins que são próprios da comunidade nacional como um todo, como um sujeito de direito internacional dotado de existência cultural e moral» (Gomes, 1990). A realização dos interesses nacionais não acaba, portanto, simplesmente com uma eficaz (boa?) diplomacia económica ${ }^{14}$.

\section{A "intervenção": documentos acordados entre o estado português e as instituições internacionais; parceiros económicos, variáveis económicas, demais documentação (alterações dos pesos dos parceiros; causas das alterações; padronização dos comportamentos económicos dos parceiros) $)^{15}$}

Para começar, vejamos a documentação oficial trocada entre o estado português e as instituições internacionais. Tanto aquando do memorando original como aquando das revisões regulares do programa, assinam-se "Cartas de Intenções" 
que o ministro das finanças (português) envia aos directores do Fundo e à cúpula da União (pelo menos ao BCE, Comissão e Eurogrupo) (a mesma carta é enviada para ambos). Nestas, o governo, para além de declarar o empenho em prosseguir políticas e objectivos do Memorando, descreve os progressos alcançados bem como medidas adicionais que entenda importantes para atingir tais objectivos. Em anexo, seguem o Memorando de Políticas Económicas e Financeiras (MPEF) e o Memorando Técnico de Entendimento (TMU), para o FMI, e o Memorando de Entendimento sobre as Condicionalidades de Política Económica (MECPE) para a União Europeia. Nestes (explicando de forma muito resumida), detalham-se mais as medidas e as previsões macroeconómicas, de dívida e de défice públicos, "racionalização" do sector público, protecção do sistema financeiro, entre outros. Também se pormenorizam os prazos em que cada uma das medidas deverá estar implementada e o seu estado.

Analisando os memorandos, não se encontra explicitamente qualquer referência a política externa (ou a alterações de substância nesta). Quando a trocas comerciais, saliente-se, no Memorando de Políticas Económicas e Financeiras (do FMI) de Outubro de 2012, na Quinta Revisão Regular do Programa de Assistência Económica e Financeira, que «External adjustment is proceeding rapidly. The current account deficit has improved by five percentage points of GDP over the past year, and nine points from the trough in late 2008, with exports making the largest contribution to the improvement. Sustained adjustment will be needed to reduce Portugal's very large net external debts. Despite the weakening external environment, growing exports to non euro area trade partners with better growth prospects over the next year will help maintain some momentum. Over the medium-term, we are committed to ensuring the sustainability of the strong performance to date through a reform program that facilitates the adjustment of relative prices across our economy, enabling our firms to become more competitive, grow and create employment», bem como «work on removing legal and administrative barriers to trade in the economically very significant services sector is well advanced» ${ }^{16}$. Já no mesmo documento, mas da Quarta Revisão Regular, se afirmava que «despite slowing demand in key trade partners, we expect exports to continue to contribute strongly to growth and external adjustment $»^{17}$. No campo meramente económico, este é, sem sombra de dúvidas o enfoque, «focus[ing] the investment priorities in projects that present a positive cost-benefit ratio and contribute to the competitiveness of Portuguese exports, namely in the port and freight rail sectors», ou «the set-up of the procedures for requesting 
VAT exemptions for exporting firms and to simplify procedures associated with indirect exports» ${ }^{18}$. E reconhece-se, nessa mesma avaliação (mas também já nas anteriores), que "in the short term, however, weaker demand from trading partners remains the main downside risk to external adjustment, [as well as] an upward revision in domestic demand and imports ${ }^{19,20}$. O essencial desta política fica contido em «improve effectiveness of existing instruments dealing with export promotion and access to finance and support the reallocation of resources towards the tradable sector». Note-se que essencialmente são constatações, não propriamente propostas (concretas), e que não é feita qualquer referência à diplomacia económica, comercial ou outra. Quase nenhumas considerações são feitas quanto às importações.

Quanto aos parceiros e variáveis económicas, as mais recentes estatísticas económicas apontam para um crescimento regular das exportações, enquanto as importações registam uma evolução mais instável nos últimos anos. Quanto ao ano de 2013, as exportações cresceram $5,7 \%$ e as importações $1,3 \%$, mas, mais significativamente, o saldo da balança comercial de bens e serviços torna-se positivo nesse mesmo ano, pela primeira vez em largas décadas. Entre 2012 e 2013 salienta-se, na distribuição geográfica das exportações de bens, a redução do peso da quota das exportações para a Europa $(71,1 \%$ para $70,2 \%)$ e o aumento da quota das exportações para o Magrebe (de 2,3\% para 3,2\%). Os principais clientes de Portugal continuam a ser a Espanha, Alemanha e França, com quase metade do total das exportações portuguesas em 2013. Não há alterações de relevo entre a estrutura dos principais países para onde Portugal exporta, salientando-se apenas pequenas diminuições do peso da Alemanha e Itália, e aumentos para Espanha e outros países (que não os 10 principais). Ao mesmo tempo, o Brasil substitui a China entre esses 10 países principais. Quanto às importações, a União Europeia (com 72,3\% do total), e a Espanha, França e Alemanha em particular (no conjunto, com mais de metade do total importado) destacam-se como países de origem das importações. Saliente-se o aumento da Angola e Rússia, e diminuições da Espanha, Brasil, e outros países nessa estrutura. Não detalharemos aqui mais quanto ao comércio de bens e de serviços de forma desagregada, bem como aos principais grupos de produtos importados e exportados. Por fim, quanto ao investimento directo estrangeiro, notamos, quanto ao IDE em Portugal, que a União Europeia continua a ser a grande origem deste (93\% em 2013), sendo que os cinco principais países (Espanha, França, Reino Unido, Alemanha e Bélgica) viram aumentar a sua quota nesta lista de 56,8\% para 78,4\% de 2012 para 2013; 
e, fora da União Europeia, apenas a Suíça e o Brasil fazem parte dos 10 maiores investidores estrangeiros em Portugal. Se o investimento tinha vindo a evoluir positivamente desde 2009, tem uma quebra neste último ano de 2013. A União Europeia é também o principal destino do investimento directo estrangeiro português (com um aumento de 82,5\% em 2012 para 93\% em 2013), tendo-se verificado maiores alterações no peso do investimento por países de destino. Os Países Baixos continuam a liderar o ranking dos países de destino, com quase dois terços do total investido (embora com uma quebra de $69,1 \%$ para $63,1 \%$ ), e os países que se seguem, Alemanha e Espanha, vêm aumentar o seu peso significativamente (de $0,5 \%$ para $16,1 \%$, e de $4,4 \%$ para $8,4 \%$, respectivamente). Note-se ainda que a evolução do investimento directo em Portugal no estrangeiro é mais irregular, tendo vindo a diminuir desde 2011, mas a manter-se bem acima dos valores de 2009 e 2010. Mais uma vez, não entraremos em detalhes quanto aos sectores para onde este mais foi encaminhado ${ }^{21}$.

\section{Conclusão: foram ou não as relações externas portuguesas afetadas significativamente pela intervenção da troika? (alterações de prioridades e objetivos do Estado português?)}

Por fim, depois de analisarmos a política externa portuguesa durante as últimas décadas e, em particular, os propósitos que se apontam para o período do programa de assistência; em que consiste a nova diplomacia económica largamente incentivada pelos agentes políticos, em analisarmos o conteúdo dos acordos entre o estado Português e as instituições internacionais, bem como as alterações das variáveis macroeconómicas, particularmente de comércio e investimento internacionais, nos últimos anos; podemos dizer que há uma alteração das relações externas portuguesas com a intervenção da troika, embora com uma série de reservas que, em seguida, expomos.

No que toca à Política Externa Portuguesa, não há alteração dos eixos estruturantes ou adicionamento de mais algum eixo - mesmo quanto ao que toca à diplomacia económica, é difícil perceber (perspectivar) se esta será uma tendência (eixo) de longo-prazo, ou se será uma estratégia somente durante o período de vigência dos programas da troika ou enquanto medidas de austeridade forem percebidas, pelo(s) governo(s) em funções como necessárias. E duvidamos que esta diplomacia económica possa ser tida como um novo eixo da Política Externa Portuguesa, pelo menos no presente - poderemos apenas vê-la como uma estratégia para as 
relações externas, mesmo as relações estabelecidas nos pilares tradicionais (assim, pode ter mudado os pilares tradicionais na sua própria substância (e propósito?), mas não é, segundo a nossa consideração, um novo pilar).

Para além disto, registámos que não existem menções significativas nos memorandos, revisões ou avaliações a questões de política externa ou relações externas. Mesmo importações, exportações e saldo da balança comercial são temas que (estranhamente?) não fazem parte, pelo menos, de forma muito denunciada, de tais acordos (quanto a metas, objectivos que os governos deverão atingir, etc.).

Portanto, há alterações nas relações externas de tipo económico durante a intervenção, com propósitos que se coadunam com os da intervenção. Ou seja, se há alterações, elas dão-se sobretudo no âmbito económico, e não são propriamente muito significativas (olhamos, por exemplo, para as prioridades, principais parceiros, etc.). E no panorama geral da Política Externa Portuguesa, nomeadamente olhando para os pilares, não há, de facto, alterações significativas. Assim, e olhando sempre para dados concretos da intervenção - acordos, discursos, estatísticas, etc. - focámos a nossa atenção no país "receptor" desse programa de assistência, e analisando dados quantitativos e qualitativos que nos permitissem perceber os impactos dessa intervenção no domínio que nos interessava, evitando assim percepções que, à partida, olhassem apenas para os interesses dos grandes estados por detrás destas instituições (e que as financiam), ou das políticas externas de tais países, assumindo estas organizações como meros instrumentos para manutenção e aquisição de mais poder no sistema internacional. Acreditamos que o facto de termos evitado tal olhar nos concedeu um conhecimento mais rico acerca dos impactos do programa de assistência na Política Externa Portuguesa.

\section{Referências bibliográficas}

AICEP Portugal Global, Portugal - Ficha País (março 2014). Disponível em: http://www.portugalglobal.pt/pt/biblioteca/livrariadigital/portugalfichapais.pdf (consultado a 2014-03-24).

ALMEIDA, Paulo Roberto de. 2009. Bases conceituais de uma política externa nacional, in MARTINS, Estevão C. de Rezende \& Miriam G. Saraiva (orgs.). Brasil - União Europeia - América do Sul: Anos 2010-2020. Rio de Janeiro: Fundação Konrad Adenauer, pp. 228-243. Disponível em: www.pralmeida.org/05DocsPRA/1929BasesConceitPExtNacBook. pdf (consultado a 2014-03-24).

BANCO DE PORTUGAL. 2011. Portugal: Programa de Assistência Financeira UE/FMI 2011-2014. Lisboa, Serviço de Edições e Publicações do Banco de Portugal. 
BELLUCCI, Paolo; Marina Costa LOBO; Michael S. LEWIS-BECK. 2012. Economic crisis and elections: The European periphery. Electoral Studies: An international Journal, Volume 31, Issue 3, Pages 469-642 (September 2012).

BERRIDGE, Geoff; Alan JAMES. 2003. A dictionary of diplomacy, 2nd ed. - Houndmills: Palgrave.

BRESSER-PEREIRA, Luiz Carlos. 2010. A crise financeira global e depois: um novo capitalismo?. Novos estudos - CEBRAP [online], n. 86 [consultado pela última vez a 2014-03-22], pp. 51-72. Disponível em: <http://dx.doi.org/10.1590/S0101-33002010000100003>. p. 53.

CASTRO, Joana. 2008. “A diplomacia económica em Portugal”, Revista da Faculdade de Ciências Humanas e Sociais. Porto: Edições Universidade Fernando Pessoa. ISSN 1646-0502. 5 (2008), pp. 218-228. Disponível em: http://hdl.handle.net/10284/912 (consultado a 2014-01-11).

CATARINO, João Ricardo; Jaime Fonseca. 2013. Sustentabilidade Financeira e Orçamental em Contexto de Crise Global Numa Europa de Moeda Única. Seqüência (Florianópolis), n. 67, p. 21-51, dez. 2013. http://dx.doi.org/10.5007/2177-7055.2013v34n67p21.

COSTA, Francisco Seixas da. 2002. Diplomacia Europeia. Instituições, alargamento e o futuro da União. Lisboa: Dom Quixote.

COSTA, Carla Guapo (org.). 2009. New frontiers for economic diplomacy: some contributions on strategic issues based on the International Conference "New frontiers for economic diplomacy”. Lisboa: Universidade Técnica de Lisboa, Instituto Superior de Ciências Sociais e Políticas.

CRAVINHO, João Gomes. 2011. "Novas coordenadas da política externa portuguesa”, JANUS 2011-2012 - Anuário de Relações Exteriores, As grandes redes de conhecimento; Zonas de crise na geopolítica mundial; Portugal num mundo em mudança, p. 162, OBSERVARE Universidade Autónoma de Lisboa. Lisboa: Público Comunicação Social, SA.. Disponível em: http://janusonline.pt/popups2011_2012/2011_2012_3_3_12.pdf (consultado a 2014-01-11).

DIÁRIO DA REPÚBLICA, 1.a série - N.o 216 - 9 de Novembro de 2006, 7783. Disponível em: http://dre.pt/pdf1sdip/2006/11/21600/77837784.PDF (consultado a 2014-03-24).

DOUGHERTY, James E.; PFALTZGRAFF, Robert L. (2003 [2001]). Relações Internacionais: as teorias em confronto. Lisboa: Gradiva.

FARTO, Manuel; Sérgio NUNES; Henrique MORAIS; dir. Luís MOITA. 2007. A nova diplomacia económica: análise e perspectivas. Lisboa: EDIUAL.

FERREIRA, José Medeiros. 1988. Portugal - os próximos vinte anos, IV vol. (Posição de Portugal no Mundo). Lisboa: Fundação Calouste Gulbenkian.

FERREIRA, Manuel Ennes; GONÇALVES, Francisco Rocha. 2009. Diplomacia económica e empresas de bandeira: os casos da Galp e da Unicer em Angola. Relações Internacionais [online], $\mathrm{n}^{\circ}$ 24, pp. 115-133. Disponível em: http://www.scielo.gpeari.mctes.pt/scielo.php?scrip$\mathrm{t}=$ sci_arttext\&pid=S1645-91992009000400012\&lng=pt\&nrm=iso (consultado a 2014-03-24).

FREIRE, Maria Raquel; VINHA, Luís da (2011), Política externa: modelos, actores e dinâmicas, in Maria Raquel Freire (org.), Política Externa: As Relações Internacionais em Mudança. Coimbra: Imprensa da Universidade de Coimbra, pp. 13-54. 
FREIRE, A. \& J. SANTANA-PEREIRA. 2012. 'Portugal 2011: The victory of the neoliberal right, the defeat of the left', Portuguese Journal of Social Science 11: 2, pp. 179-187, doi: 10.1386/pjss.11.2.179_2.

GALITO, Maria Sousa. 2011. Diplomacia Económica de Portugal no Atlântico - Lusofonia e EUA. CI-CPRI, AI, n¹5, pp. 1-149. Disponível em: http://www.ci-cpri.com/wp-content/ uploads/2011/12/DE-Portugal-Atlantico3.pdf (consultado a 2014-03-24).

GALITO, Maria Sousa. 2012. Diplomacia Económica - Vantagens e Desvantagens, ISEG -UTL. Disponível em: http://pascal.iseg.utl.pt/ socius/eventos/JDE/Apresentacoes/Maria_Sousa_Galito_texto.pdf (consultado a 2014-03-24).

GOMES, Gonçalo Santa Clara. 1990. A política externa e a diplomacia numa estratégia nacional. Instituto da Defesa Nacional. Ano XV; $N^{\circ}$ 56. Disponível em: http://comum.rcaap. pt/handle/123456789/2669 (consultado a 2014-03-24).

HUDSON, Valerie M.; VORE, Christopher S. (1995). Foreign Policy Analisis Yesterday, Today, and Tomorrow. Mershon International Studies Review, Vol. 39, No. 2 (Oct., 1995), pp. 209-238.

HUDSON, Valerie M. (2005). Foreign Policy Analysis: Actor-Specific Theory and the Ground of International Relations. Foreign Policy Analysis, 1, pp. 1-30.

INE, Estatísticas do Comércio Internacional 2012 (Edição 2013). Disponível em: http://www. ine.pt/ngt_server/attachfileu.jsp?look_parentBoui=163129262\&att_display=n\&att_downloa$\mathrm{d}=\mathrm{y}$ (consultado a 2014-03-24).

INE, Estatísticas do Comércio Internacional - janeiro 2014. Disponível em: http://www.ine. pt/ngt_server/attachfileu.jsp?look_parentBoui=214867844\&att_display=n\&att_download $=y$ (consultado a 2014-03-24).

KISSINGER, Henry. 1996. Diplomacia. Lisboa: Gradiva.

LEAL, Ana Catarina Pereira Mendes. 2007. A diplomacia económica em Portugal no século XXI: que papel no investimento directo português no exterior?. Negócios Estrangeiros $\mathrm{N}^{\circ}$ 11.1, pp. 207-310. Disponível em: https://infoeuropa.eurocid.pt/opac/?func=service\&doc_library=CIE01\&doc_number=000039786\&line_number $=0001 \&$ func_code=WEB-FULL\&service_type=MEDIA (consultado a 2014-03-24).

LESSER, Ian O.. 2006. Portugal and the southern Mediterranean: transatlantic interest and strategies. Lisbon: Luso-American Development Foundation. Disponível em http:// www.flad.pt/documentos/1215711903Y9vXZ5wp0Cb71UB9.pdf (consultado a 2014-01-12).

MAGALHÃES, José Calvet de. 2005. A diplomacia pura. Lisboa: Bizâncio.

MARTINS, Marco António. 2011. Portugal e os BRIC: numa perspectiva da diplomacia pública e da autopoiesis. Comunicação apresentada no Colóquio Internacional: Portugal entre desassossegos e desafios, Centro de Estudos Sociais. Faculdade de Economia da Universidade de Coimbra. Disponível em: http://hdl.handle.net/10174/2606 (consultado a 2014-03-24).

Memorandum of Economic and Financial Policies (Attachment II), Quarta Revisão Regular do Programa de Assistência Económica e Financeira - junho 2012. http://www.portugal. gov.pt/pt/os-ministerios/primeiro-ministro/secretarios-de-estado/secretario-de-estado-adjunto-do-primeiro-ministro/documentos-oficiais/memorandos.aspx (consultado a 2014-03-24). 
Memorandum of Economic and Financial Policies (Attachment II), Quinta Revisão Regular do Programa de Assistência Económica e Financeira - outubro 2012. http://www.portugal. gov.pt/pt/os-ministerios/primeiro-ministro/secretarios-de-estado/secretario-de-estado-adjunto-do-primeiro-ministro/documentos-oficiais/memorandos.aspx (consultado a 2014-03-24).

Memorandum of Economic and Financial Policies (Attachment I), Décima Revisão Regular do Programa de Assistência Económica e Financeira - Janeiro 2014. http://www.portugal. gov.pt/pt/os-ministerios/primeiro-ministro/secretarios-de-estado/secretario-de-estado-adjunto-do-primeiro-ministro/documentos-oficiais/memorandos.aspx (consultado a 2014-03-24).

Memorandum of Understanding on Specific Economic Policy Conditionality, Sexta Revisão Regular do Programa de Assistência Económica e Financeira - Dezembro 2012. http:// www.portugal.gov.pt/pt/os-ministerios/primeiro-ministro/secretarios-de-estado/secretariode-estado-adjunto-do-primeiro-ministro/documentos-oficiais/memorandos.aspx (consultado a 2014-03-24).

Memorandum of Understanding on Specific Economic Policy Conditionality, Décima Revisão Regular do Programa de Assistência Económica e Financeira - Fevereiro 2014.

MENDES, Pedro Emanuel (2012). Portugal e a Europa. Factores de afastamento e aproximação da política externa portuguesa (1970-1978). CEPESE (Centro de Estudos da População, Economia e Sociedade).

Ministério da Economia, da Inovação e do Desenvolvimento, Gabinete de Estratégia e Estudos, Síntese Estatística de Comércio Internacional, $N^{\circ} 12 / 2010$. Disponível em: www. gee.min-economia.pt/?cfl=18479 (consultado a 2014-03-24). http://www.portugal.gov.pt/pt/ os-ministerios/primeiro-ministro/secretarios-de-estado/secretario-de-estado-adjunto-do-primeiro-ministro/documentos-oficiais/memorandos.aspx (consultado a 2014-03-24).

MONGIARDIM, Maria Regina de (2007). Diplomacia. Coimbra: Almedina.

NEGÓCIOS ESTRANGEIROS - SEMINÁRIO DIPLOMÁTICO, JANEIRO DE 2012. Edição digital, Ano I. n. ${ }^{\circ}$ 1. Publicação do Ministério dos Negócios Estrangeiros. Lisboa. Disponível em: http://idi.mne.pt/images/rev_ne/ne_2012_01.pdf (consultado a 2014-03-24).

NEGÓCIOS ESTRANGEIROS - SEMINÁRIO DIPLOMÁTICO, JANEIRO DE 2013. Edição digital, Ano II. n. ${ }^{\circ}$ 2. Publicação do Ministério dos Negócios Estrangeiros. Lisboa. Disponível em: www.negociosestrangeiros.idiplomatico.pt/revistas/NegEstranJan2013.pdf (consultado a 2014-03-24).

NOGUEIRA, João Pontes; MESSARI, Nizar (2005). Teoria das Relações Internacionais: correntes e debates. Rio de Janeiro: Editora Elsevier.

ORTIZ, Isabel e Matthew CUMMINS. 2013. The Age of Austerity: A review of public expenditures and adjustment measures in 181 countries. Initiative for Policy Dialogue and the South Centre, Working Paper [consultado pela última vez a 2014-03-22]. Disponível em: http://policydialogue.org/files/publications/Age_of_Austerity_Ortiz_and_Cummins.pdf .p. 11 .

PATRÍCIO, Raquel (2014), Política Externa, in MENDES, Nuno Canas e COUTINHO, Francisco Pereira (orgs.) (2014), Enciclopédia das Relações Internacionais. Lisboa: Dom Quixote.

PROGRAMA DO XIV GOVERNO CONSTITUCIONAL, 1999-2002. Disponível em: http:// www.portugal.gov.pt/media/464048/GC14.pdf (consultado a 2014-01-13). 
PROGRAMA DO XV GOVERNO CONSTITUCIONAL, 2002-2004. Disponível em: http:// www.portugal.gov.pt/media/464051/GC15.pdf (consultado a 2014-01-13).

PROGRAMA DO XVI GOVERNO CONSTITUCIONAL, 2004-2005. Disponível em: http:// www.portugal.gov.pt/media/464054/GC16.pdf (consultado a 2014-01-13).

PROGRAMA DO XVII GOVERNO CONSTITUCIONAL, 2005-2009. Disponível em: http:// www.portugal.gov.pt/media/464060/GC17.pdf (consultado a 2014-01-13).

PROGRAMA DO XVIII GOVERNO CONSTITUCIONAL, 2009-2011. Disponível em: http:// www.portugal.gov.pt/media/468569/gc18.pdf (consultado a 2014-01-13).

PROGRAMA DO XIX GOVERNO CONSTITUCIONAL, 2011-presente. Disponível em: http:// www.portugal.gov.pt/media/130538/programa_gc19.pdf (consultado a 2014-01-13).

RADOS, Milan (2003). A Política Externa da União Europeia. Lisboa: O Espírito das Leis Editora.

RANA, Kishan S.; CHATTERJEE, Bipul. Introduction: The Role of Embassies, in RANA, Kishan S.; CHATTERJEE, Bipul (eds.). 2011. Economic Diplomacy: India's Experience. CUTS International.

SILVA, Manuel Carlos. 2013. Crise, democracia e desenvolvimento: o lugar semiperiférico de Portugal. RES. Revista Española de Sociología, ISSN-e 1578-2824, №. 19, pp. 153-168 [consultado pela última vez a 2014-03-22]. Disponível em: http://www.fes-web.org/uploads/ files/res/res19/11.pdf.

SOUSA, Fernando de (dir.) (2005). Dicionário de Relações Internacionais. Porto: Afrontamento.

TEIXEIRA, Nuno Severiano. 2010. "Breve ensaio sobre a política externa portuguesa." Relações Internacionais [online] n. 28 [consultado a 2014-01-11], pp. 51-60. Disponível em: http://www.scielo.gpeari.mctes.pt/scielo.php?script=sci_arttext\&pid=S164591992010000400004\&lng=pt\&nrm=iso ISSN 1645-9199.

VICENTE, Paulo Carvalho. 2013. "Integração europeia, federalismo e o lugar de Portugal (1960-2002)". JANUS.NET e-journal of International Relations, Vol. 4, N. ${ }^{\circ} 1$. Consultado [online] em 2014-01-11, http://observare.ual.pt/janus.net/images/stories/PDF/vol4_n1/pt/ pt_vol4_n1_art3.pdf

1 Uma versão inicial deste texto foi apresentada no Congresso "Portugal, 40 anos de democracia", na Faculdade de Psicologia e Ciências da Educação da Universidade do Porto (28 de Março de 2014), e será futuramente publicado nas actas do mesmo

2 Uma boa introdução acerca das causas desta crise, e, em particular, uma cronologia detalhada dos principais momentos que influíram nesta podem ser encontrados em ALEXANDRE, Fernando, et. al.. A Crise Financeira Internacional, Coimbra: Imprensa da Universidade de Coimbra, 2009

3 Esta resposta forte e decidida não durou muito tempo, na realidade, o que desmentiu aqueles que previam, por estas reacções, que estaríamos perante um "novo capitalismo", menos financeirizado e mais burocrático; mais comercial e produtivo, e assente no conhecimento do que no financeiro; e numa democracia mais orientada para políticas sociais e mais participativa. 
4 «Following this logic, the social welfare state was depicted as unaffordable and burdensome, which ultimately reduced competitiveness and discouraged growth» (Ortiz \& Cummins, 2013).

5 Segundo o mesmo estudo de Ortiz \& Cummins (2013), a Europa tem vários países a tentar implementar todas estas medidas (incluindo Portugal), sendo as medidas mais frequentemente discutidas e adoptadas a reforma do sistema de pensões e o aumento dos impostos sobre o consumo. Mas as reformas no sistema de saúde, a racionalização das transferências sociais e a redução dos salários (reduzindo a função pública, eliminando regimes salariais especiais ou complementos salariais) também são medidas adoptadas por grande parte dos países desenvolvidos.

6 Para Francisco Seixas da Costa (2002), «a integração de Portugal na Europa comunitária representou uma das opções mais relevantes que os decisores políticos nacionais tomaram no século XX. Essa opção, pelas suas consequências profundas no próprio perfil externo do país, acabará por erigir-se como um elemento determinante no posicionamento futuro de Portugal na cena mundial», opção que foi normalizadora da vida democrática, introduzindo um grande aumento da qualidade de vida, num saldo que é francamente positivo, não existindo à data outra opção com «condições de melhor proteger esses mesmos interesses», e atendendo a que os fundos comunitários serviram de alavanca ao «largo consenso pró-europeu» alcançado então.

7 Note-se que Severiano Teixeira (2010) propõe uma nova "vertente dos valores" para a Política Externa Portuguesa, sobrepondo os direitos humanos e os valores democráticos aos resultados estritamente económicos, e, em suma, incitando a um novo equilíbrio entre interesses e valores na política externa deste país.

8 É com esse propósito que é aprovada em Conselho de Ministros a Resolução n. ${ }^{\circ}$ 152/2006, fixando um novo regime aplicável à diplomacia económica para cumprir tais objectivos. (Diário da República 1.a série - N.o 216, 2006)

9 O Programa do XIX Governo Constitucional (2011), liderado por Pedro Passos Coelho e em funções desde 2011 até ao presente é aquele em que mais se denota o impacto da crise financeira internacional, sendo mais curto e vago do que todos os que analisámos anteriormente (desde 1999 até à actualidade). Por um lado, há que compreender a crise das dívidas soberanias que atacou fortemente Portugal, uma forte recessão económica, e indicadores macroeconómicos muito negativos, como o desemprego, consumo, investimento, entre outros, condições que levaram à viragem final rumo à diplomacia económica, pretendendo recuperar a credibilidade externa e "promoção e atracção do investimento e da internacionalização da economia portuguesa» (p. 104) praticamente como únicos objectivos de política externa. Para além disso, note-se que tal governo considera que a diplomacia tradicionalmente atribuída ao Ministério dos Negócios Estrangeiros está plenamente consolidada em opções europeias, atlânticas e lusófonas consensuais e consistentes. Daqui para a frente, todas as variantes não exclusivamente económicas deverão ser «credíveis» e "estratégicas e economicamente relevante[s]» (p. 105), vindo as componentes financeira e económica à frente de todas as outras. O multilateralismo e a CPLP, por exemplo, serão vistos apenas como plataforma aprofundamento das relações comerciais e de investimentos, voltando-se a reforçar, por outro lado, relações bilaterais privilegiadas com os Estados Unidos da América.

10 Quanto a uma discussão muito sucinta sobre o conceito de "diplomacia económica", este poderá ser definido como: «(1) Diplomacy concerned with economic policy questions, including the work of delegations to conferences sponsored by bodies such as the World Trade Organization. While distinct from the commercial diplomacy of diplomatic missions, it also includes that part of their work concerned with monitoring and reporting on economic policies and developments in the receiving state and advising on how best to influence them. (2) Diplomacy which employs economic resources, either as rewards or sanctions, in pursuit of a particular foreign policy objective. This is sometimes known as 'economic statecraft'». Assim, encontra-se bastante próximo do de diplomacia comercial: "The work of diplomatic missions in support of the home country's business and finance sectors. Distinct from although obviously closely related to economic diplomacy, 
it is now common for commercial diplomacy to include the promotion of inward and outward investment, as well as trade. Important features of this work are the supply to the sending state's trade ministry and businessmen (especially those from small businesses) of information about export and investment opportunities, maintaining contact with the businessmen and chambers of commerce of the receiving state, and organizing and supporting trade missions from home. In American diplomatic missions this work is currently undertaken largely by officers of the foreign commercial service of the Department of Commerce, assisted by the mission's economic officer and possibly others». Quanto à diferença entre um conceito e outro: «Is it [economic diplomacy] different from commercial diplomacy? Opinions differ; some of those that have worked in this métier tend to see commercial diplomacy as a subset of the wider compendium of economic diplomacy. For instance, typically, commercial diplomacy would not include the management of economic aid - either as a donor or as a recipient - but that would clearly fall within the rubric of economic diplomacy. The same may apply to managing relations with international economic organisations, such as the World Bank and the International Monetary Fund, or the UN regional commissions. (...) For business enterprises, industry bodies, consultants, users, and all those directly concerned with overseas economic activities, such distinctions are not of great interest. They are much more concerned with the way official agencies and the business promotional bodies can help them to navigate their way in their profit-oriented activities in foreign markets. They are the true customers of economic diplomacy». Concluímos que, provavelmente, o termo a utilizar no caso português deveria ser "diplomacia comercial" e não "diplomacia económica", embora explicações mais aprofundadas destes conceitos não caibam no âmbito deste trabalho. (Berridge \& James, 2003; Rana \& Chatterjee, 2011);

11 Propósitos, aliás, que já eram proclamados no ano anterior, no mesmo Seminário: «se países bem mais desenvolvidos e prósperos reúnem nas embaixadas e consulados as suas redes externas - a diplomática, a comercial e a turística - porque haveria Portugal, que até está em dificuldades e não por acaso até precisa, como de pão para a boca, de uma política externa económica e empresarial eficaz, de manter a ineficiente singularidade de não conjugar, não coordenar, e às vezes nem tão pouco articular todas as suas energias e fontes de ação económica externa?», ou «devo (...) dizer algo mais sobre duas das prioridades de política externa que, no momento atual de Portugal, elegi, desde o primeiro dia, como principais - tendo o cuidado de acrescentar que não esgotam o elenco das nossas tarefas. Refiro-me à melhoria da perceção externa sobre Portugal e ao empenhamento total na diplomacia económica.» (Negócios Estrangeiros - Seminário Diplomático, 2012).

12 Aliás, o novo modelo institucional da diplomacia económica, no que toca à articulação mais concretizada entre o Ministério dos Negócios Estrangeiros e a AICEP pode ser encontrado em: Negócios Estrangeiros - Seminário Diplomático, 2012, pp. 48-54.

13 Ver ainda Galito (2012)

14 Quanto a considerações mais teóricas, ver os já incontornáveis (nomeadamente, para uma melhor compreensão do "fenómeno diplomático") Kissinger (1996) ou Magalhães (2005). Para estudos de caso bastante aprofundados, e nomeadamente para a análise do caso português, Costa (2009) ou Farto, Nunes \& Morais (2007).

15 Todos os documentos a que recorremos neste ponto e que se referem ao acordo entre o estado português e as instituições internacionais (os chamados "memorandos") estão disponíveis em: http://www.portugal.gov.pt/pt/os-ministerios/primeiro-ministro/secretarios-de-estado/secretario-de -estado-adjunto-do-primeiro-ministro/documentos-oficiais/memorandos.aspx (consultado a 2014-03-24). Demais relatórios, de propostas para a Reforma do Estado (pela OCDE e FMI), bem como as avaliações pelas instituições internacionais aquando das revisões regulares do Programa de Assistência Económica e Financeira estão disponíveis em: http://www.portugal.gov.pt/pt/os-ministerios/primeiro-ministro/secretarios-de-estado/secretario-de-estado-adjunto-do-primeiro-ministro/ documentos-oficiais/relatorios.aspx (consultado a 2014-03-24). 
16 "We have accelerated the drafting of the needed legislation, and, as a result, over half of the amendments to sector specific legislation have already been approved either by government or by Parliament and are now in effect. The remaining 23 amendments required to complete this effort will be submitted to Parliament by end-October 2012. We will step up the efforts to establish a well functioning online platform (Point of Single Contact) which simplifies the procedures for establishing and operating firms in these sectors. In addition, we have submitted to Parliament a new horizontal framework law concerning the professional bodies of highly regulated professions (such as lawyers, accountants, architects), easing access to these professions and limiting anticompetitive practices». Portugal - Memorandum of Economic and Financial Policies (Attachment II), Quinta Revisão Regular do Programa de Assistência Económica e Financeira - outubro 2012. Itálicos nossos.

17 Portugal - Memorandum of Economic and Financial Policies (Attachment II), Quarta Revisão Regular do Programa de Assistência Económica e Financeira - junho 2012. Itálicos nossos.

18 Memorandum of Understanding on Specific Economic Policy Conditionality, Décima Revisão Regular do Programa de Assistência Económica e Financeira - Fevereiro 2014.

19 Portugal - Memorandum of Economic and Financial Policies (Attachment I), Décima Revisão Regular do Programa de Assistência Económica e Financeira - Janeiro 2014.

20 Outras medidas propostas para este propósito, são: «measures to facilitate access to finance for SMEs and assess the effectiveness of EU-compatible government-sponsored export credit insurance schemes with a view to take appropriate measures to promote exports (...) especially those in the most productive and innovative segments of the economy, while ensuring these initiatives will not pose significant fiscal risks» (Memorandum of Understanding on Specific Economic Policy Conditionality, Sexta Revisão Regular do Programa de Assistência Económica e Financeira - Dezembro 2012); rever leis do trabalho e restantes regulamentos para os portos; entre outros.

21 Estes dados, alguns ainda de carácter provisório ou preliminar, têm origem no Banco de Portugal e no Instituto Nacional de Estatística. Ainda assim, para um bom resumo das alterações nos parceiros e variáveis económicas, quer com que toca ao comércio internacional quer ao investimento internacional, remetemos para o relatório da Agência para o Investimento e Comércio Externo de Portugal, a partir de onde a maioria dos dados que discutimos foram analisados (AICEP, 2014). Poderão ainda ser consultados, para informação mais detalhada: Ministério da Economia, 2010 (para dados muito detalhados, sobretudo do período entre 2005 e 2010); INE, 2013 (para dados muito detalhados, sobretudo do período entre 2005 e 2012, e uma visão de médio-prazo sobre as alterações que ocorreram neste período); INE, 2014 (sobretudo para os anos mais recentes, dados de 2012 até ao início de 2014). 